Вісник Харківського національного університету імені В.Н. Каразіна Серія "Математика, прикладна математика і механіка" Том 92,2020 , с. $25-43$

УДК 517.977.58: 51-74
Visnyk of V.N.Karazin Kharkiv National University Ser. "Mathematics, Applied Mathematics and Mechanics"

Vol. 92, 2020, p. 25-43

DOI: $10.26565 / 2221-5646-2020-92-03$

\title{
One numerical approach to optimal control the linear heat conduction processes
}

\author{
I. Sh. Nevliudov ${ }^{1}$, Yu. V. Romashov ${ }^{1,2}$ \\ ${ }^{1}$ Kharkiv National University of Radio Electronics, \\ Kharkiv, Nauky Ave. 14, 61166,Ukraine \\ ${ }^{2}$ V. N. Karazin Kharkiv National University, \\ Kharkiv, 4 Svobody Sq., 61022, Ukraine \\ igor.nevliudov@nure.ua,yurii.romashov@nure.ua
}

It is proposed the generalized numerical based approaches to optimal control the heat conduction processes based on solving the especially built ordinary differential equations. The example of using the proposed approaches is discussed and it is shown that using these approaches can allow to decrease almost twice the transient time required for heating-up structures.

Keywords: control; modeling; optimization; methods; heat conduction.

Невлюдов І. Ш., Ромашов Ю. В. Обчислювальний підхід щодо оптимального управління процесами лінійної теплопровідності. Запропоновано обчислювальні підходи щодо оптимального управління процесами теплопровідності. Розглянуто приклад та показано, що оптимізація управління може зменшити вдвічі час, необхідний для нагрівання конструкцій.

Ключові слова: управління; моделювання; оптимізація; методи; теплопровідність.

\begin{abstract}
Невлюдов И. Ш., Ромашов Ю. В. Численный подход к оптимальному управлению процессами линейной теплопроводности. Предложены вычислительные подходы для оптимального управления процессами теплопроводности. Рассмотрен пример и показано, что оптимизация управления может уменьшить вдвое время, необходимое для нагрева конструкций.

Ключевые слова: управление; моделирование; оптимизация; методы; теплопроводность
\end{abstract}

2010 Mathematics Subject Classification: 49Mxx; 80Axx.

\section{Introduction}

The optimal control of the heat conduction processes is the in current interest scientific problem due to its relations with the global challenges of rational using the different kinds of power equipments by means the integrating control and design [1], by means introducing the new types of fuels like the biomass [1,2], as well as by means optimizing the thermal states during the industries processes [3]

(C) I. Sh. Nevliudov, Yu. V. Romashov, 2020 
and others ways. The current state of the optimal control of power equipments can be characterized as using the particular approaches for the particular tasks $[1,2,3]$ and as having no the all-accepted engineering approaches like using the different kinds of governors for automation [4] for example. Considering these circumstances, the optimal control of heat conduction processes are having a lot attentions now $[5,6,7,8,9,10]$. The most of existing research including the cited above are about different mathematical approaches and results corresponding with the optimal control. Really, the main difficulties of the optimal control problems are in general due to necessity of consideration the transients between the different states of researched systems which are defined by means the differential equations usually. As the result of that, considering the optimal control requires the complicated and often specific mathematical approaches in some cases like in [11] for example. Thus, the mathematical complications significantly limit the opportunities of engineering implementing the fundamental results existing in the fields of of the optimal control. Besides, the most of known approaches are suitable for the particular problems only and can not be used for engineering applications usually.

It is clearly understood, the approaches based on the to be suitably programmed numerical methods allowing to solve the problems using the computers are the most useful for engineering applications of the optimal control. Considering this circumstance, the purpose of this research is to develop the generalized numerical based approaches to optimal control the heat conduction processes useful for engineering applications. To realize this purpose, we will solve the follows tasks:

- it will be proposed the generalized mathematical formulation of the problem about the optimal control for the heat conduction processes represented by the partial differential equation;

- to solve the problem about the optimal control for the heat conduction processes it will be developed the numerical approaches based on reducing to the especially built ordinary differential equations;

- the particular example of using the developed approaches will be considered to illustrate their application technique.

All these will allow to give the clear representation of the proposed approaches and the technique of their using to solve the engineering problems about the optimal control of the heat conduction processes in different industrial systems.

\section{The generalized mathematical formulation of the problem}

To give the generalized approaches to solve the problem about the optimal control of the heat conduction processes it is necessary to represent the generalized but not particular mathematical formulation of the considered problem. Let consider the heat conduction processes in the domain which is imagined as consisting of the points of Euclidean space $\mathrm{E}^{3}$, and let denote as $\Upsilon$ and $v$ the sets of the internal and boundary points $P \in \mathrm{E}^{3}$ of that domain (pic. 1a). We will choose the arbitrary point $O \in \mathrm{E}^{3}$, and we will define each other point $P \in \mathrm{E}^{3}$ by the 
radius vector $\mathbf{r}=\overrightarrow{O P}$ (pic. 1a). The point $P \in \mathrm{E}^{3}$ defined by the radius vector $\mathbf{r}$ will be noted as $P(\mathbf{r})$ (pic. 1a). The temperature $T$ can be different in each point of the considered domain $\Upsilon \bigcup v$ and it can be changing during the time $t \geq 0$. Thus, the temperature $T$ depends both the $\mathbf{r}$ position vector both the scalar time $t$ so it can be represented as $T=T(\mathbf{r}, t)$.

Let the considered domain is having some given temperature field $T=T_{\text {cur }}(\mathbf{r})$ in some given current moment of the time $t=t_{\text {cur }}$, but it is necessary to change this temperature field of the considered domain so the temperature will be having the required given field $T=T_{\text {req }}(\mathbf{r})$ at the some undefined moment of the time $t_{\text {tr }}$ defining the final of the transients, and it is necessary to find the optimal control providing the required quality of the transients under the existing restrictions on the temperature field during the transients. Such presented above formulation represents the most general verbal description of the problem about the optimal control of changing the temperature field of structures, but further we will represent the formal mathematical formulation of this problem as it is possible in general.

We will consider the most general case of the linear heat conduction processes defining by the different typical kinds of thermal interacting on the considered domain's boundary (pic. 1b):

$$
v=v_{T} \bigcup v_{q} \bigcup v_{\alpha}
$$

where $v_{T}$ is the part of the boundary $v$ having the given temperature as the result of interacting with the surrounding environment; $v_{q}$ is the part of the boundary $v$ obtaining the given heat flow from the surrounding environment; $v_{\alpha}$ is the part of the boundary $v$ having the given heat transfer with the surrounding environment.

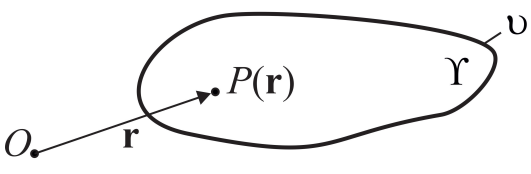

a)

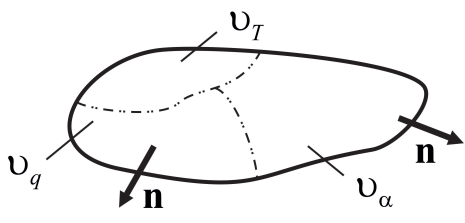

b)

Pic. 1. The considered domain (a) and the constituents (b) of its boundary

It will be supposed, that it is exist the time dependent vector $\mathbf{u}=\mathbf{u}(t)$ consisted of some parameters and it is named as the control vector or just the control which can have influencing on the temperature state of the considered domain according with the well-known heat conduction principles:

$$
\begin{gathered}
c \frac{\partial T}{\partial t}=\lambda \nabla^{2} T+Q(\mathbf{r}, \mathbf{u}) \quad \forall P(\mathbf{r}) \in \Upsilon, t>t_{\text {cur }}, \\
T\left(\mathbf{r}, t_{\text {cur }}\right)=T_{\text {cur }}(\mathbf{r}) \quad \forall P(\mathbf{r}) \in \Upsilon,
\end{gathered}
$$




$$
\begin{gathered}
T(\mathbf{r}, t)=T_{v}(\mathbf{r}, \mathbf{u}) \quad \forall P(\mathbf{r}) \in v_{T}, t \geq t_{\mathrm{cur}}, \\
-\lambda \vec{\nabla} T(\mathbf{r}, t) \cdot \mathbf{n}=q_{v}(\mathbf{r}, \mathbf{u}) \quad \forall P(\mathbf{r}) \in v_{q}, t \geq t_{\mathrm{cur}}, \\
-\lambda \vec{\nabla} T(\mathbf{r}, t) \cdot \mathbf{n}=\alpha\left(T(\mathbf{r}, t)-T_{\alpha}(\mathbf{r}, \mathbf{u})\right) \quad \forall P(\mathbf{r}) \in v_{\alpha}, t \geq t_{\mathrm{cur}},
\end{gathered}
$$

where $c$ and $\lambda$ are the heat capacity and the thermal conductivity of the material of the considered domain; $\nabla^{2}$ is the Laplace operator; $Q$ is the intensity of the internal heat sources inside the material of the considered domain; $T_{v}$ is the given temperature on the part $v_{T}$ of the boundary $v ; \vec{\nabla}$ is the gradient of the scalar field; $\mathbf{n}$ is the unit external normal vector to the boundary $v$ (see pic. $1 b$ ); $q_{v}$ is the given heat flow thru the part $v_{q}$ of the boundary $v ; \alpha$ is the heat transfer coefficient thru the part $v_{\alpha}$ of the boundary $v$ and $T_{\alpha}$ is the temperature of the environment surround the part $v_{\alpha}$ of the boundary $v$.

It is necessary to note, the mathematical model (1)-(6) foresees the temperature state can be changed by means the control vector only, so that the depending of the temperature on the time is due to only the $\mathbf{u}=\mathbf{u}(t)$.

Further, it will be required to find the control vector $\mathbf{u}$ so that in the some undefined time moment $t=t_{\text {tr }}$ the temperature field in the considered domain will become to given:

$$
T\left(\mathbf{r}, t_{\mathrm{tr}}\right)=T_{\text {req }}(\mathbf{r}) \quad \forall P(\mathbf{r}) \in \Upsilon, t \geq t_{\mathrm{tr}} .
$$

During the times $t_{\mathrm{cur}} \leq t \leq t_{\mathrm{tr}}$ corresponding to the transients between the current and required temperature states it is necessary satisfying some limitations. The nature of such limitations can be different. These limitations can be due to the strength restrictions considering with the thermal stresses or they can be due to the finite power of the heating sources providing the control. It is really impossible to foresee all possible kinds of limitations on the temperature state and the control, but it is possible to imagine that such limitations are could be reduces to some condition on the temperature and the control vector which must be satisfied:

$$
\Theta(T(\mathbf{r}, t), \mathbf{u}(t))=0 \quad \forall P(\mathbf{r}) \in \Upsilon \bigcup v, t \geq t_{\text {cur }},
$$

where $\Theta$ is some function defining the limitations on the temperature state and the control vector.

The limitations on the temperature state and on the control vector are especially represented as (8) in this research to simplify the follows expositions to represent the essence of the proposed numerical approaches for solving the problem about the optimal control of the heat conduction processes. Really, in general case it is possible to have such limitations represented by not the equality, but by the inequality, it is possible to have several limitations like (8) and other difficulties. At the same time, the most simple view (8) of these limitations is fully sufficient to represent the general idea of the numerical approaches will be proposed further, and different difficulties like due to inequalities for example or others can be reduced separately. 
It is obviously that the required temperature field (7) can be achieved by a lot of different controls $\mathbf{u}$ satisfying the limitation (8), but it is necessary to find the optimal control providing the required qualities of the transients from the current state (3) to the required state (7). It is impossible to foresee all kinds of requirements to the transients and to formulate the most general form of their mathematical representing. The most used requirement is the minimum time of the transients, but to have understood about the power of the generality of the proposed approaches it is necessary to give some general ways to formulate these requirements to the transients. First of all, to formulate the requirements to the transients it is necessary to consider some set $v_{\Psi}$ of the points $\in \mathrm{E}^{3}$ defining some part of the considered domain $\Upsilon \bigcup v$; to have the definiteness we will consider further $v_{\Psi} \in v$. Next, it is necessary to consider some function of the time:

$$
\psi_{T}(t)=\int_{v_{\Psi}} \Psi(T) d v_{\Psi} \quad \forall t \geq t_{\mathrm{cur}},
$$

where $\Psi$ is some given function is needed to define the requirements to the transients.

The sense of the function (9) is predefined by the choosing the $\Psi$ function. For example, the function (9)will represent the power of heat flow thru the surface $v_{\Psi}$ in the case of $\Psi(T)=-\lambda \vec{\nabla} T$. Finally, that relation (9) will help to formulate the requirement to the transient as follows:

$$
\varphi \rightarrow \min : \varphi=\int_{t_{\text {cur }}}^{t_{\mathrm{tr}}} \Phi\left(\psi_{T}, \mathbf{u}\right) d t
$$

where $\Phi$ is some given function is also needed to define the requirements to the transients.

Using the relations (9), (10) to define the requirements to the qualities of the transients will allow to consider the different kinds of such requirements including the minimal time of the transients, the minimal supplied power to realize the necessary given transients and others. It will not be discussed in this research because we will try to propose the generalized numerical approaches for solving the problem about the optimal control of the heat conduction processes independently to the kind of the particular formulations. Thus, we can give the generalized formulation of the problem about the optimal control of the heat conduction processes: the problem about the optimal control of the heat conduction processes is in finding the control vector $\mathbf{u}$ allowing to transform the current temperature state (3) to the required temperature state (7) so that it control vector provide the qualities (9), (10) of the transients under the limitations (8) on the temperature state (1)-(6). It is clearly understood, the initial and boundary conditions (3)-(6) must satisfy some requirements providing the existence of the unique solution of the initial-boundary-value problem (1)-(6). The required temperature field (7) also cannot be arbitrary because this temperature field must be permissible for realizing. At the same time, all these restrictions are not discussed above. Nevertheless, the presented above formulation (1)-(6) includes all necessaryitems to represent 
the principal idea of the numerical approaches will be considered next. Some of the restrictions necessary to provide numerical solving of the problem will be specified next if necessary.

\section{The generalized approach for numerical solving the problem}

The engineering applications of the optimal control the heat conduction processes require the numerical approaches because the analytical approaches are possible in limited numbers of the particular cases and are not applicable for all possible cases. Next, we will consider the principal ideas of some approach which will allow in principle to solve numerically the problem about the optimal control for the heat conduction processes. It is understood that each particular realization of these principal ideas can include some specific difficulties will be different for each considered particular problem and these difficulties cannot be foresaw under considering the general formulation of the problem. Thus further, we will consider actually the principal ideas of the numerical approach taking into account the difficulties of solving the problem about the optimal control principally inherent from the considered heat conduction processes, but we will not take into account the possible particular features.

To propose the numerical approach it is necessary to understand that the most principal difficulties of the optimal control of heat conduction processes are due to the partial differential equation representing the model of these processes by means the initial-boundary-value problem (1)-(6). Considering this circumstance, first principal idea of the proposed approach to numerical solving is to reduce the partial differential equation (2) to the ordinary differential equations. To do this, it is possible to use the different known approaches, but we will use the wellknown method of grids. Following this method, we will introduce the grid as the set of predefined $n$ nodal points of the considered domain defined by the following radius vectors:

$$
\mathbf{r}_{k} \in \Upsilon \bigcup v, \quad k=1,2, \ldots, n,
$$

where $\mathbf{r}_{k}$ is the radius vector defining the nodal point with the number $k$.

To having the grid (11), we can introduce the vector of the nodal values of the temperature:

$$
\mathbf{x}_{n}(t)=\left(\begin{array}{llll}
T_{1}(t) & T_{2}(t) & \ldots & T_{n}(t)
\end{array}\right)^{T},
$$

where $T_{k}(t)=T\left(\mathbf{r}_{k}, t\right), k=1,2, \ldots, n$ and ${ }^{T}$ is the transpose symbol.

Using the vector (12), and the well-known finite differences technique we can reduce the partial differential equation (2) with the boundary conditions (4)-(6) to the ordinary differential equations with the initial conditions occurring from the initial condition (3) as follows:

$$
\frac{d \mathbf{x}_{n}}{d t}=\mathbf{A}_{n} \mathbf{x}_{n}+\mathbf{B}_{n} \mathbf{u}, \quad \mathbf{x}_{n}\left(t_{\text {cur }}\right)=\mathbf{x}_{n(\mathrm{cur})},
$$

where $\mathbf{A}_{n}$ and $\mathbf{B}_{n}$ is the matrices built by using the finite differences for the initial-boundary-value problem (1)-(6) and the grid (11) and the nodal values $(12) ; \mathbf{x}_{n \text { (cur) }}=\left(T_{\text {cur }}\left(\mathbf{r}_{1}\right) T_{\text {cur }}\left(\mathbf{r}_{2}\right) \ldots T_{\text {cur }}\left(\mathbf{r}_{n}\right)\right)^{T}$. 
The discrete representation (13) of the temperature state (1)-(6) is due to the significant assumption about linearly of the initial-boundary-value problem (1)(6). Thus, we have the ordinary differential equations with the initial conditions (13) representing the discretisation of the initial-boundary-value problem (1)-(6). Due to this circumstance, we can solve numerically the Cauchy problem (13) by using any known numerical method, like the Runge-Kutta methods, for all given control vectors $\mathbf{u}$. At the same time, the problem about the optimal control is in finding the optimal control which will allow transforming the current state (3) to the required state (7) under the limitation (8) and providing the optimal transient (9), (10). Thus, the grid (11) and the nodal values (12) will allow to reduce the condition (7), the limitation (8) and the requirement (9), (10) to the transients to the following views respectively

$$
\begin{gathered}
\mathbf{x}_{n}\left(t_{\mathrm{tr}}\right)=\mathbf{x}_{n(\mathrm{req})}, \\
\Theta_{n}\left(\mathbf{x}_{n}(t), \mathbf{u}(t)\right)=0 \quad \forall t \geq t_{\mathrm{cur}}, \\
\varphi_{n} \rightarrow \min : \varphi_{n}=\int_{t_{\mathrm{cur}}}^{t_{\mathrm{tr}}} \Phi_{n}\left(\mathbf{x}_{n}, \mathbf{u}\right) d t
\end{gathered}
$$

where $\mathbf{x}_{n \text { (req) }}=\left(T_{\text {req }}\left(\mathbf{r}_{1}\right) T_{\text {req }}\left(\mathbf{r}_{2}\right) \ldots T_{\text {req }}\left(\mathbf{r}_{n}\right)\right)^{T} ; \Theta_{n}$ and $\Phi_{n}$ are the discrete representations of the relation (8) and (9), (10) respectively.

The problem about the optimal control of the heat conduction processes is reduced to the finding the optimal control $\mathbf{u}$ which will allow transforming the current state defined by the initial condition (13) to the required state (14) under the limitation (15) and providing the optimal transient (16) for the temperature state defined by the Cauchy problem (13). We must finding the control vector $\mathbf{u}$ as the function of the time $t$, but the most general approach to find some unknown function is to formulate the ordinary differential equation and the initial conditions so that this unknown function will be the solution of the corresponding Cauchy problem because it is possible to use the well-known numerical methods for to solve that problem. Thus, second principal idea of the proposed numerical approach to solving the problem about the optimal control of the heat conduction processes is in defining the unknown control vector as the solution of the follows Cauchy problem:

$$
\frac{d \mathbf{u}}{d t}=\mathbf{p}(t, \mathbf{u}), \quad \mathbf{u}\left(t_{\text {cur }}\right)=\mathbf{u}_{\mathrm{cur}},
$$

where $\mathbf{p}$ is some function defining the permissible velocity of the control vector and $\mathbf{u}_{\text {cur }}$ is the permissible control vector at the time moment $t=t_{\text {cur }}$.

It is naturally, finding the control vector by solving the Cauchy problem (17) requires having the permissible velocity $\mathbf{p}$ and the permissible initial $\mathbf{u}_{\text {cur }}$ of the control vector $\mathbf{u}$. To find the initial permissible control vector $\mathbf{u}_{\text {cur }}$ we will use the condition (15) which will be reduced using the initial conditions from the Cauchy problems (13) and (17) as follows:

$$
\Theta_{n}\left(\mathbf{x}_{n(\text { cur })}, \mathbf{u}_{\text {cur }}\right)=0
$$


The relation (18) will allow building the equations necessary to find the initial permissible control vector $\mathbf{u}_{\mathrm{cur}}$, but view of these equations and technique of their building is significantly defined by the view of the relation (18) predefined by the constraint (15). It is seems, to find the initial permissible control vector $\mathbf{u}_{\text {cur }}$ the relation (18) in general can be resolved approximately only and the least squares method can be used for it because it will allow to have the necessary number of the equations. In some particular cases the relation (18) will give directly the necessary equations necessary to find exactly the control vector $\mathbf{u}_{\text {cur }}$ as will be shown further on the considered example. To find the permissible velocity $\mathbf{p}$ of the control vector we will use the the condition (15), but it had been especially transformed as follows:

$$
\frac{\partial \Theta_{n}}{\partial \mathbf{x}_{n}} \frac{d \mathbf{x}_{n}}{d t}+\frac{\partial \Theta_{n}}{\partial \mathbf{u}} \frac{d \mathbf{u}}{d t}=0 \quad \forall t \geq t_{\text {cur }} .
$$

Taking into account the relation (19), we can suppose that

$$
\frac{\partial \Theta_{n}}{\partial \mathbf{x}_{n}}=\mathbf{v}_{n}^{T}\left(\mathbf{x}_{n}, \mathbf{u}\right), \frac{\partial \Theta_{n}}{\partial \mathbf{u}}=\mathbf{w}_{n}^{T}\left(\mathbf{x}_{n}, \mathbf{u}\right),
$$

where $\mathbf{v}_{n}$ and $\mathbf{w}_{n}$ are some vector functions.

The introduced vector functions (20) allow having the suitable representing the relation (19) and it will help formulating the condition to find the permissible velocity of the control vector:

$$
\mathbf{v}_{n}^{T}\left(\mathbf{x}_{n}, \mathbf{u}\right) \frac{d \mathbf{x}_{n}}{d t}+\mathbf{w}_{n}^{T}\left(\mathbf{x}_{n}, \mathbf{u}\right) \mathbf{p}=0 \quad \forall t \geq t_{\text {cur }} .
$$

The reduced relation (21) allows to build all necessary equations to approximately find the permissible velocity $\mathbf{p}$ of the control vector by using the least squares method in a general case. Really, the least squares method will lead to the linear algebraical equations:

$$
\left(\mathbf{v}_{n} \cdot \mathbf{v}_{n}^{T}\right) \cdot \frac{d \mathbf{x}_{n}}{d t}+\left(\mathbf{w}_{n} \cdot \mathbf{w}_{n}^{T}\right) \cdot \mathbf{p}=0 \quad \forall t \geq t_{\text {cur }} .
$$

Solution of the linear algebraical equations (22) can be represented by using the inverse matrix as follows:

$$
\mathbf{p}=-\left(\mathbf{w}_{n} \cdot \mathbf{w}_{n}^{T}\right)^{-1} \cdot\left(\mathbf{v}_{n} \cdot \mathbf{v}_{n}^{T}\right) \cdot \frac{d \mathbf{x}_{n}}{d t} \quad \forall t \geq t_{\text {cur }} .
$$

It is clearly understood that the permissible velocity $\mathbf{p}$ of the control vector from the differential equation (17) is defined by the relation (23) considering with the Cauchy problem (13), which will allow defining the vectors $\mathbf{x}_{n}$ and $\frac{d \mathbf{x}_{n}}{d t}$ for the given time $t$ and the given control vector $\mathbf{u}$.

The control vector defined by the Cauchy problem (17) will allow infinite changing the temperature state not violating the limitation (15), if the velocity of this control vector will be defined by the relations (23) with the Cauchy problem (13) and the initial control vector will be defined by the relation (18). At the same time, it is not required to change the temperature state infinitely, but it is 
required to change the temperature state finitely to the given state defined by the relation (14). Thus, in some time moment $t=t_{\mathrm{sw}}$ it is necessary to change the velocity of the control vector and this changing can be imagined as switching. To find the switching time $t_{\mathrm{sw}}$, it is necessary first of all to define the required control vector and to do this we will use the mathematical model (13) of the temperature state as well as the required temperature state defined by the condition (14). As the result of all this, we can write the condition for defining the required control vector providing the required temperature state (14) as follows:

$$
\mathbf{A}_{n} \mathbf{x}_{n(\text { req })}+\mathbf{B}_{n} \mathbf{u}_{\text {req }}=0
$$

where $\mathbf{u}_{\text {req }}$ is the required control vector providing the required temperature state (14).

The permissible kind of the required temperature field $T_{\text {req }}$ used in the condition (7) was not defined above in the general formulation (1)-(10) of the problem about the optimal control of the heat conduction processes. At the same time, it is obviously, that the required temperature field cannot be arbitrary and must providing the unique solution of the considered problem including. Let assume, that the required temperature field is such so it is existed the unique control vector $\mathbf{u}_{\mathrm{req}}$ will be satisfied the relation (24). This assumption can be imagined as the principal possibility of providing the required temperature field (7) represented thru its discretisation (14) by means the control vector $\mathbf{u}$. Let define the time moment $t=t_{\mathrm{sw}}$ so to satisfy the follows condition:

$$
\mathbf{v}_{n}^{T}\left(\mathbf{x}_{n}, \mathbf{u}\right) \frac{d \mathbf{x}_{n}}{d t}+\mathbf{w}_{n}^{T}\left(\mathbf{x}_{n}, \mathbf{u}\right)\left(\mathbf{u}_{\mathrm{req}}-\mathbf{u}\right) \delta\left(t-t_{\mathrm{sw}}\right)=0,
$$

where $\mathbf{x}_{n}, \mathbf{u}, \frac{d \mathbf{x}_{n}}{d t}$ are all defined at the time moment $t=t_{\mathrm{sw}} 4 \delta$ is the Dirac function.

Using the relations (24), (25) we can formulate the third principal idea of the proposed approach to solve the problem about the optimal control of the heat conduction processes. This third principal idea is to satisfy the limitation (15) and the condition (14) defining the required temperature state by formulating the Cauchy problem to find the control vector as follows (pic. 2):

$$
\frac{d \mathbf{u}}{d t}=\left\{\begin{array}{ll}
\mathbf{p}(t, \mathbf{u}), & t_{\mathrm{cur}} \leq t \leq t_{\mathrm{sw}} \\
\left(\mathbf{u}_{\mathrm{req}}-\mathbf{u}\right) \delta\left(t-t_{\mathrm{sw}}\right), & t>t_{\mathrm{sw}}
\end{array} \quad \mathbf{u}\left(t_{\mathrm{cur}}\right)=\mathbf{u}_{\mathrm{cur}} .\right.
$$

The switching time $t_{\mathrm{sw}}$ involved to the differential equation (26) is defined thru the relation (25) of course, and it is naturally to suppose that this relation (25) will allow finding the set of the time moments $t_{\mathrm{sw}}$ which are the set of the discrete or continuous values in some interval:

$$
t_{\mathrm{sw}}^{\min } \leq t_{\mathrm{sw}} \leq t_{\mathrm{sw}}^{\max },
$$

where $t_{\mathrm{sw}}^{\min }$ and $t_{\mathrm{sw}}^{\max }$ are some minimum and maximum values of the switching times $t_{\mathrm{sw}}$ satisfying the relation (25). 


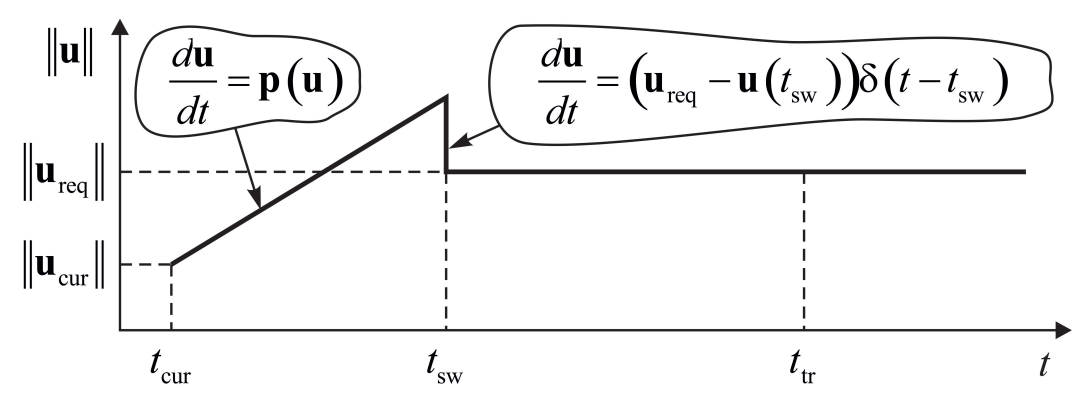

Pic. 2. Defining the velocity of the control vector

Solving numerically the Cauchy problem (26), we can choose the switching time $t_{\mathrm{sw}}$ arbitrary from the interval (27) and we will can estimating the transient time $t_{\mathrm{tr}}$ corresponded this choice. Thus, by numerical solving the Cauchy problem (26) for the different chosen switching times $t_{\mathrm{sw}}$, we can build the function:

$$
t_{\mathrm{tr}}=t_{\mathrm{tr}}\left(t_{\mathrm{sw}}\right) \text {. }
$$

This function (28) with the requirement (16) to the transients will allow to have the follows function:

$$
\varphi_{n}=\varphi_{n}\left(t_{\mathrm{sw}}\right) .
$$

Fourth principal idea of the proposed numerical approach to solve the problem about the optimal control the heat conduction processes is to minimize the approximately built function (29) inside the interval (27).

\section{Example about the optimal control of the heat conduction}

The discussed above generalized numerical approach to solve the problem about the optimal control the heat conduction processes is included only the principals ideas, but somethings are not fully presented, because it can be specified only considering to the each particular problem. Really, the approaches for defining of the permissible velocity using the relation (21), the required control vector using the relation (24) as well as the switching time from the relation (26) is not clear from the presented above principle ideas. Such approaches can have the differences for each particular case, but the proposed general scheme based on the discussed above the principal ideas is same for the different kinds of the problems about the optimal control the heat conduction processes. The follows example will show the possible application of the discussed above principal ideas as well as influencing the particulars on the solving process.

As example, we will consider the problem about the optimal control of heatingup the planar wall (pic. 3a) representing the typical structures of the thermal and nuclear power plants. We will assume that the heat flow is existed only along the direction of the plane wall thickness, the initial temperature field of the planar wall is uniform, the temperature state of the planar wall is controlled by the temperature of one edge of this wall, but second edge has the thermal isolation 
(pic. 3a). Corresponding these assumptions, the temperature field $T=T(z, t)$ is depended on the $z$ coordinate along the thickness of the plane wall (pic. $3 \mathrm{a}$ ) and on the time $t \geq 0$, and the generalized mathematical formulation of the problem (1)-(6) will be reduced to the follows [12]:

$$
\begin{gathered}
\Upsilon: 0<z<l, \quad v_{T}: z=0, \quad v_{q}: z=l, \quad v_{\alpha}=\oslash, \\
\frac{\partial T}{\partial t}=a \frac{\partial^{2} T}{\partial z^{2}}, \quad \forall 0<z<l, \quad t>0, \\
T(z, 0)=T_{\text {cur }}, \quad \forall 0<z<l, \\
T(z, t)=u(t), \quad z=0, \quad \forall t \geq 0, \\
\frac{\partial T}{\partial z}(z, t)=0, \quad z=l, \quad \forall t \geq 0,
\end{gathered}
$$

where $l$ is the thickness of the planar wall (pic. 3a); $a$ is the temperature conduction coefficient of the structural material of the planar wall; $T_{\text {cur }}=$ const is the given current temperature at the time moment $t=0 ; u$ is the control.

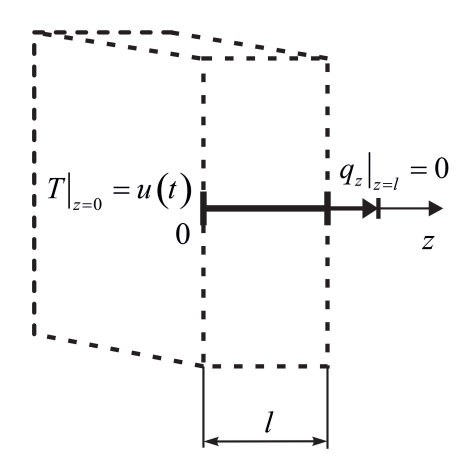

a)

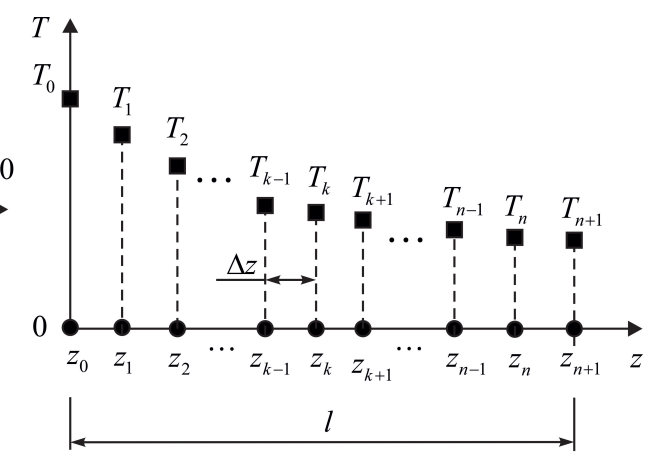

b)

Pic. 3. The planar wall (a) and discretisation of their temperature state (b)

Further, we will find the control $u$ so that in the some undefined time moment $t=t_{\mathrm{tr}}$ the temperature field of the considered planar wall will become to given:

$$
T\left(z, t_{\mathrm{tr}}\right)=T_{\mathrm{req}} \quad \forall 0 \leq z \leq l, t \geq t_{\mathrm{tr}},
$$

where $T_{\text {req }}=$ const is the given required temperature so that $T_{\text {req }}>T_{\text {cur }}$.

During the times $0 \leq t \leq t_{\mathrm{tr}}$ corresponding to the transients between the current and required temperature states it is necessary satisfying the strength restriction which can be represented for the planar wall as follows:

$$
|u(t)-T(l, t)| \leq \frac{2[\sigma]}{E \beta} \quad \forall t \geq 0,
$$

where $[\sigma], E$ and $\beta$ are the the given permissible stress, the Young's modulus and the temperature expansion coefficient of the structural material of the planar wall. 
The nature of the strength restriction (36) is not for discussing in this research, but it is necessary to note that this restriction (36) represents limiting of the temperature stresses on the planar wall with the fixed edges $z=0$ and $z=l$ under the temperature field with the linear distribution along the thickness.

The requirement (9), (10) on the transients will be reduced in this example to one of interesting particular cases corresponding to the high speed performance problem:

$$
t_{\mathrm{tr}} \rightarrow \min
$$

Thus, we have the enough correspondence between the generalized formulation (1)-(10) and the considered particular example (30)-(37).

Following the proposed approach, we will introduce the grid with $n$ nodes inside the interval $0<z<l$ as show on pic. $3 \mathrm{~b}$; this grid will have the $n+2$ nodes with the coordinates which will allow introducing the temperature nodes values:

$$
z_{k}=k \cdot \Delta z, \quad T_{k}(t)=T\left(z_{k}, t\right), \quad k=0,1,2, \ldots, n, n+1,
$$

where $z_{k}$ is the coordinate of the grid node and $T_{k}$ is the nodal value of the temperature all corresponded with the grid node number $k ; \Delta z=\frac{l}{n+1}$ is the step of the grid.

We will use the follows well-known formulas for approximate differentiating:

$$
\frac{\partial^{2} T_{k}}{\partial z^{2}}=\frac{T_{k-1}-2 T_{k}+T_{k+1}}{\Delta z^{2}}, \frac{\partial T_{k}}{\partial z}=\frac{3 T_{k}-4 T_{k-1}+T_{k-2}}{2 \Delta z} .
$$

The boundary condition (33) and second formula (39) with the boundary condition (34) allows to write:

$$
T_{0}=u, \quad T_{n+1}=\frac{4}{3} T_{n}-\frac{1}{3} T_{n-1} .
$$

First formula (39) can be used for the "internal"nodes $k=1,2, \ldots, n$ only, but and formula (17) is used to exclude the temperature $T_{n+1}$ in the equation for the $k=n$ node. As the result, we will obtain the discrete approximation of the heat conduction problem (30)-(34) in the form (13) in which we will have [12]

$$
\begin{aligned}
& \mathbf{x}_{n}(t)=\left(\begin{array}{llll}
T_{1}(t) & T_{2}(t) & \ldots & \left.T_{n}(t)\right)^{T}, \mathbf{u}=(u),
\end{array}\right. \\
& \mathbf{A}_{n}=\frac{a}{\Delta z^{2}}\left(\begin{array}{cccccccccc}
-2 & 1 & 0 & 0 & 0 & \ldots & 0 & 0 & 0 & 0 \\
1 & -2 & 1 & 0 & 0 & \ldots & 0 & 0 & 0 & 0 \\
0 & 1 & -2 & 1 & 0 & \ldots & 0 & 0 & 0 & 0 \\
0 & 0 & 1 & -2 & 1 & \ldots & 0 & 0 & 0 & 0 \\
\vdots & \vdots & \vdots & \vdots & \vdots & \ddots & \vdots & \vdots & \vdots & \vdots \\
0 & 0 & 0 & 0 & 0 & \ldots & 1 & -2 & 1 & 0 \\
0 & 0 & 0 & 0 & 0 & \ldots & 0 & 1 & -2 & 1 \\
0 & 0 & 0 & 0 & 0 & \ldots & 0 & 0 & 2 / 3 & -2 / 3
\end{array}\right), \\
& \mathbf{B}_{n}=\frac{a}{\Delta z^{2}}\left(\begin{array}{cccccccccc}
1 & 0 & 0 & 0 & 0 & \ldots & 0 & 0 & 0 & 0
\end{array}\right)^{T},
\end{aligned}
$$




$$
\mathbf{x}_{n \text { (cur) }}=\left(\begin{array}{llll}
T_{\text {cur }} & T_{\text {cur }} & \ldots & T_{\text {cur }}
\end{array}\right)^{T} .
$$

Thus, we have the discrete approximation (38)-(44) of the considered heat conduction process (30)-(34) and this discrete approximation (38)-(44) is the similar to the general representation was discussed previously in the proposed approach. Using the discrete approximation (38)-(44) of the considered heat conduction process, we can reduce the conditions (35), (36) regarding the general approach as follows:

$$
\begin{gathered}
\mathbf{x}_{n(\text { req })}=\left(\begin{array}{llll}
T_{\text {req }} & T_{\text {req }} & \ldots & T_{\text {req }}
\end{array}\right)^{T}, \\
\left|u(t)-\left(\frac{4}{3} T_{n}(t)-\frac{1}{3} T_{n-1}(t)\right)\right| \leq \frac{2[\sigma]}{E \beta} \quad \forall t \geq 0 .
\end{gathered}
$$

It seems, the condition (46) is not same kinds than the considered above relation (18), but we show that the condition (46) will be reduced to the view (18). Really, from the physical sense of the considered particular problem we have $u(t) \geq\left(\frac{4}{3} T_{n}(t)-\frac{1}{3} T_{n-1}(t)\right)$. Besides, corresponding to the high speed performance problem (37), we can to reduce the inequality in the relation (46) to the equality. As the results of all these, we can reducing the relation (46) to the follows view:

$$
u(t)-\left(\frac{4}{3} T_{n}(t)-\frac{1}{3} T_{n-1}(t)\right)=\frac{2[\sigma]}{E \beta} \quad \forall t \geq 0 .
$$

The condition (47) is the same kind that the condition (18). Defining the required control $\mathbf{u}_{\text {req }}$ is significantly simpler in this considering example comparing the general case (24):

$$
u_{\text {req }}=T_{\text {req. }}
$$

Using the condition (47) with the relation (48), and we can beginning to build the resolving Cauchy problem generally represented above as (26). In this considering example, the resolving Cauchy problem generally represented as (26) will be reduced to one ordinary first order differential equation with the initial condition:

$$
\frac{d u}{d t}=\left\{\begin{array}{ll}
\mathbf{w}_{n}^{T} \frac{d \mathbf{x}_{n}}{d t}, & 0 \leq t \leq t_{\mathrm{sw}} \\
-\gamma\left(u\left(t_{\mathrm{sw}}\right)-u_{\mathrm{req}}\right) \mathrm{e}^{\gamma\left(t_{\mathrm{sw}}-t\right)}, & t>t_{\mathrm{sw}}
\end{array}, u(0)=\frac{2[\sigma]}{E \beta}+T_{\mathrm{cur}}\right.
$$

where $\mathbf{w}_{n}^{T}=\left(\begin{array}{llllll}0 & 0 & \ldots & 0 & -1 / 3 & 4 / 3\end{array}\right) ; \gamma=10$ is some numerical parameter used for the exponential approximating of the Dirac function.

The Cauchy problem (49) in this considered example is principally similar to the Cauchy problem (26) in the general case. At the same time, it is necessary to define the switching time $t=t_{\mathrm{s} w}$ in the Cauchy problem (49). To do this, we will use the analogue of the relation (25) which in this particular example can having the follows view:

$$
T\left(z_{m}, t_{\mathrm{sw}}\right)=T_{\text {req }}
$$

where $m$ is the integer number can be chosen as $m=0,1,2, \ldots, n, n+1$. 
The correspondence between the particular relation (50) ant its general representation (25) is really not clear at once, but it is can be understood that the relation (50) will satisfy the general formulated relation like (50) form the physical meaning of the considered problem and it will be shown on the computational results. In any case, we can use the any of the relation (50) corresponding to any value $m=0,1,2, \ldots, n, n+1$ and to have the numerical solution of the Cauchy problem defined thru the relations (13), (41)-(44), (49), (50). As result of having such numerical solutions, we can find the transient time $t_{\text {tr }}$ for any values $m=0,1,2, \ldots, n, n+1$ :

$$
t_{\mathrm{tr}}=t_{\mathrm{tr}}(m), \quad m=0,1,2, \ldots n, n+1 .
$$

Thus, to solve the problem about the optimal control in this particular case of the high speed performance problem (37) it is necessary to minimize the numerically built function (51).

Further, we will consider some results of computer simulations for the follows input data:

$$
\begin{aligned}
& a=15 \cdot 10^{-6} \mathrm{~m} / \mathrm{s}, l=0,02 \mathrm{~m}, T_{\text {cur }}=290 \mathrm{~K}, T_{\text {req }}=790 \mathrm{~K}, \\
& \beta=10^{-5} 1 / \mathrm{K}, E=195 \mathrm{GPa},[\sigma]=160 \mathrm{MPa} .
\end{aligned}
$$

To make the computer simulations we will use the well-known and widely used 4 order Runge-Kutta method. All further shown and discussed results are corresponded to the count $n$ internal grid nodes (see pic. $3 \mathrm{~b}$ ) and to the fixed time integrating step $\Delta t$ which are defined as follows:

$$
n=31, \quad \Delta t=0,01 \mathrm{~s} .
$$

Some results of computer simulations using the proposed numerical approach are presented on the pic. 4 . The fastest heating up of the planar wall is provided for the optimal control $u$ corresponding to the value $m=18$ as shown on the pic. 4a. We can see (pic. $4 \mathrm{a}$ ) that the minimal value $t_{\text {tr }}$ corresponding to the optimal control $u$ with the value $m=18$ is approximately twice smaller than the worse results, corresponded to the controls with the values $m=0$ and $m=32$, and this circumstance illustrates the possible effect of optimization the control for industries applications. The differences between the optimal control $u$ corresponded to the value $m=18$ and the worse controls $u$ with the values $m=0$ and $m=32$ can be imagined from the pic. $4 \mathrm{~b}$. We can see that the control $u$ corresponding to the value $m=0$ is worse due to premature stopping of increasing the temperature on the edge $z=0$, but the control $u$ corresponding to the value $m=32$ is worse due to latecomer stopping of increasing the temperature on the edge $z=0$; the optimality of the control $u$ corresponded to the value $m=18$ is due to choosing the optimal moment of stopping of increasing the temperature on the edge $z=0$. It is obviously, the optimization result is significantly depended on the value $n$ of the grid's nodes, but the values (53) are seemed as sufficient in this research to show the technique of using the proposed generalized approaches. 


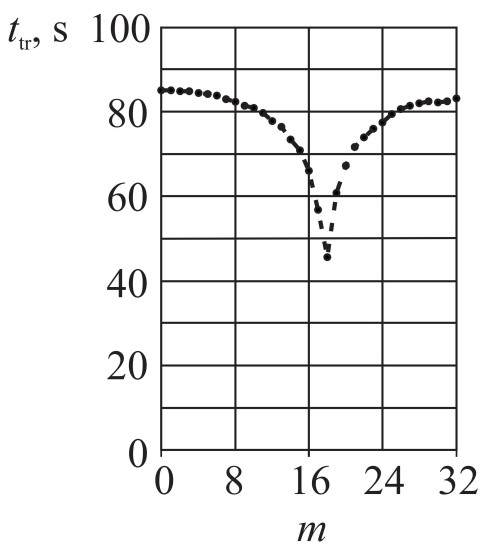

a)

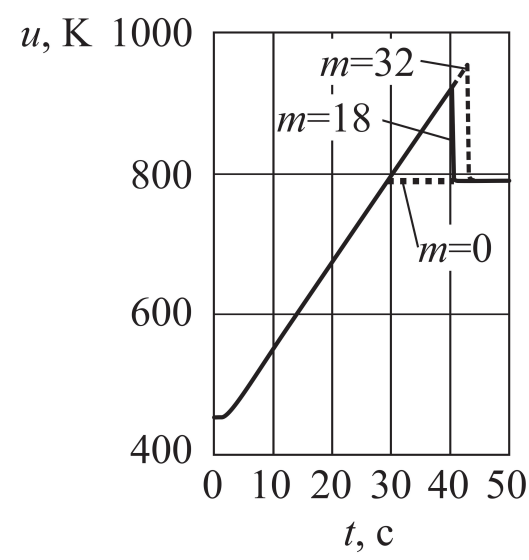

b)

Pic. 4. The optimizing process (a) and some of possible controls (b)

\section{Conclusions}

This research allow to represent and to generalize the results obtained during last three years, including the previous published results [12].

- It was proposed the generalized mathematical formulation of the problem about the optimal control for the heat conduction processes represented by the partial differential equation. At the same time, the proposed formulation not includes the necessary clarifications about the conditions which must be satisfied by the current and the required temperature fields, because it was difficult to imagine the possible origin of such conditions. Nevertheless, during the further generalized solving the formulated problem, it was established that the current and required temperature fields must be agreed with the mathematical model of the heat conduction processes so that to have possibilities to provide uniquely these temperature fields by means the control vector. It is necessary to carefully research this further.

- To solve the problem about the optimal control for the heat conduction processes it was developed the numerical approaches based on reducing to the especially built ordinary differential equations and minimization problem. This reducing is based on discretisation the heat conduction problem and on defining the unknown control vector as the numerical solution of the especially built Cauchy problem. To satisfy all limitations it is proposed to build the permissible velocity of the unknown control vector considering with the requirements of necessary switching in some moments of the time. The proposed approach includes some particulars which cannot be discussed for the generalized formulations and must be resolved for each particular case. Considering these circumstances, it is necessary to clarify further the proposed numerical approach to provide the most universal satisfying the current and required temperature fields as well as the restrictions on the transients. 
- The particular example of using the developed approaches will be considered to illustrate the application technique. It was shown that the proposed generalized mathematical formulation is fully corresponded with the considered particular example. It seems that uniform temperature fields used to define the current and required states allow having the possibilities in providing uniquely these temperature fields by means the control vector in most particular cases. It is shown that the resolving Cauchy problem can be built and the switching time can be found in the depending on the grid node choosing in this considered example. The minimization of the optimum defining parameter was reduce to finding the minimum element of the array built by numerical integrating the resolving Cauchy problems corresponded to the different possible switching times of the control. It was shown that the transient time can be decrease almost twice due to optimizing the control in the particular example at least.

All these results will allow to give the clear representation of the proposed approaches and the technique of their using to solve the engineering problems about the optimal control of the heat conduction processes in different industrial systems.

Acknowledgement. Authors thank to docent Yevhen Druzhinin from the National Technical University "Kharkiv Polytechnic Institute"for his interest to this research at the beginning state was three years ago, because some his comments were significantly helpful to understand how to solve the particular example and how to formulate further the general approach.

\section{ORCID ID}

I. Sh. Nevliudov (iD) https://orcid.org/0000-0002-9837-2309

Yu. V. Romashov (iD) https://orcid.org/0000-0001-8376-3510

\section{REFERENCES}

1. M. Hultgren, E. Ikonen, J. Kovacs. Integrated control and process design in CFB boiler design and control - application possibilities, IFAC-PapersOnLine, - 2017. - 50, 1. - P. 1997-2004. DOI: 10.1016/j.ifacol.2017.08.180

2. R. Seeber, M. Golles, N. Dourdoumas, M. Horn. Reference shaping for modelbased control of biomass grate boilers, Control Engineering Practice, - 2019. - 82. - P. 173-184. DOI: 10.1016/j.conengprac.2018.10.006

3. I. Cabeza-Gil, B. Calvo, J. Grasa, C. Franco, S. Llorente, M. A. Martinez. Thermal analysis of a cooking pan with a power control induction system, Applied Thermal Engineering, - 2020. - 180. - 115789. DOI: 10.1016/j.applthermaleng.2020.115789 
4. M. Pondini, A. Signorini, V. Colla, S. Barsali. Analysis of a simplified Steam Turbine governor model for power system stability studies, Energy Procedia, - 2019. - 158. - P. 2928-2933. DOI: 10.1016/j.egypro.2019.01.953

5. K. Kalimeris, T. Ozsari. An elementary proof of the lack of null controllability for the heat equation on the half line, Applied Mathematics Letters, - 2020. - 104. - 106241. DOI: 10.1016/j.aml.2020.106241

6. C. Letrouit. From internal to pointwise control for the 1D heat equation and minimal control time, Systems \& Control Letters, - 2019. - 133. - 104549. DOI: $10.1016 /$ j.sysconle.2019.104549

7. L. Berrahmoune. A variational approach to constrained null controllability for the heat equation, European Journal of Control. - 2020. - 52. - P. 42-48. DOI: $10.1016 /$ j.ejcon.2019.09.006

8. C. Laurent, L. Rosier. Exact controllability of semilinear heat equations in spaces of analytic functions, Annales de l'Institut Henri Poincare C, Analyse non lineaire, - 2020. - 37, 4. - P. 1047-1073. DOI: 10.1016/j.anihpc.2020.03.001

9. A. Schaum, T. Meurer. Dissipativity-based output-feedback control for a class of semilinear unstable heat equations, IFAC-PapersOnLine, - 2019. - 52, 16. - P. 316-321. DOI: 10.1016/j.ifacol.2019.11.798

10. P. Lissy. The cost of the control in the case of a minimal time of control: The example of the one-dimensional heat equation, Journal of Mathematical Analysis and Applications, - 2017. - 541, 1. - P. 497-507. DOI: 10.1016/j.jmaa.2017.01.096

11. V. I. Korobov. Time Optimality for Systems with Multidimensional Control and Vector Moment Min-Problem, Journal of Dynamical and Control Systems, - 2020. - 26. - P. 525-550. DOI: 10.1007/s10883-019-09465-2

12. I. Sh. Nevliudov, Yu. V. Romashov. The semi-discretisation method for optimizing the program control of distributed parameters systems, Bulletin of Zaporizhzhia National University. Physical and Mathematical Sciences, 2020. - 1. - P. 64-71. DOI: 10.26661/2413-6549-2020-1-08 (in Ukrainian).

\section{Обчислювальний підхід щодо оптимального управління процесами лінійної теплопровідності \\ Невлюдов І. Ш. ${ }^{1}$, Ромашов Ю. В. ${ }^{1,2}$ \\ ${ }^{1}$ Харківсъкий Начіональний Університет Радіоелектроніки проспект Науки, 14, Харків, Україна, 61166 \\ ${ }^{2}$ Харківсъкий національний університет ім. В. Н. Каразіна пл. Свободи, 4, Харків, Украӥна, 61022}

Запропоновано узагальнене математичне формулювання задачі про оптимальне управління процесами теплопровідності, що визначаються диференціальним рівнянням у частинних похідних. Запропоноване формулювання не включає необхідних 
роз'яснень щодо умов, яким повинні відповідати поточні та необхідні температурні поля. Але, в процесі узагальненого розв'язування сформульованої задачі, встановлено, що поточне та необхідне температурні поля повинні бути узгодженими із математичною моделлю теплопровідності таким чином, щоб мати можливості однозначно забезпечити ці температурні поля за допомогою належного вибору вектору управління. Для розв'язування сформульованої задачі про оптимальне управління процесами теплопровідності розроблено обчислювальні підходи, що засновані на зведенні до спеціально побудованих звичайних диференціальних рівнянь та задачі мінімізації. Це зведення засноване на дискретизації проблеми теплопровідності із застосуванням методу сіток та на визначенні невідомого вектора управління шляхом обчислювального розв'язування спеціально побудованої для цього задачі Коші. Для задоволення всіх потрібних обмежень пропонується побудувати допустиму швидкість невідомого вектора управління з урахуванням необхідності перемикання управління в деякі моменти часу. Приклад використання запропонованих узагальнених підходів розглянуто для ілюстрації техніки їхнього застосування. Показано, що запропонована узагальнена математична постановка повністю відповідає розглянутому прикладу. У цьому розглянутому прикладі можна побудувати розв'язувальну задачу Коші, а час перемикання можна знайти у залежності від вибору вузла сітки. Показано, що в розглянутому прикладі перехідний час може зменшуватися майже вдвічі за рахунок оптимізації управління. Усі ці результати дозволяють чітко уявити запропоновані підходи та техніку їхнього використання для розв'язування інженерних задач щодо оптимального управління процесами теплопровідності в різних промислових системах.

Ключові слова: управління; моделювання; оптимізація; методи; теплопровідність.

One numerical approach to optimal control the linear heat conduction processes

I. Sh. Nevliudov ${ }^{1}$, Yu. V. Romashov ${ }^{1,2}$

${ }^{1}$ Kharkiv National University of Radio Electronics 14 Nauky Ave., Kharkiv, 61166, Ukraine

${ }^{2}$ V. N. Karazin Kharkiv National University

4 Svobody sqr., Kharkiv, 61022, Ukraine

It is proposed the generalized mathematical formulation of the problem about the optimal control for the heat conduction processes representing by the partial differential equation. The proposed formulation not includes the necessary clarifications about the conditions which must be satisfied by the current and required temperature fields. But, during the generalized solving of the formulated problem, it is established that the current and required temperature fields must be agreed with the mathematical model of the heat conduction so that to have possibilities to provide uniquely these temperature fields by means the control vector. To solve the problem about the optimal control for the heat conduction processes it is developed the numerical approaches based on reducing to the especially built ordinary differential equations and minimization problem. This reducing is based on discretisation the heat conduction by using the grid method and on defining the unknown control vector as the numerical solution of the especially built Cauchy problem. To satisfy the all limitations it is proposed to build the permissible velocity of the unknown control vector considering with the requirements of necessary switching in some moments of the time. The particular example of using the proposed generalized approaches is considered to illustrate their application technique. It is shown that the proposed generalized mathematical formulation is fully corresponded with the considered particular example. In this considered particular example, the resolving Cauchy problem 
can be built and the switching time can be found in the depending on the grid node choosing. It is shown that the transient time can be decrease almost twice due to optimizing the control in the particular example at least. All these results will allow giving the clear representation of the proposed approaches and the technique of their using to solve the engineering problems about the optimal control of the heat conduction processes in different industrial systems.

Keywords: control; modeling; optimization; methods; heat conduction.

Article history: Received: 16 November 2020; Final form: 19 December 2020;

Accepted: 21 December 2020. 